\title{
Travel medicine in primary health care
}

\author{
KRZYSZTOF KORZENIEWSKI ${ }^{1,2, A-F}$
}

${ }^{1}$ Military Institute of Medicine in Warsaw, Department of Epidemiology and Tropical Medicine in Gdynia, Poland

${ }^{2}$ Polish Academy of Sciences, Gdansk Branch, Maritime and Tropical Medicine Commission, Poland

A - Study Design, B - Data Collection, C - Statistical Analysis, D - Data Interpretation, E - Manuscript Preparation, F - Literature Search, G - Funds Collection

Summary Over the last several decades, there has been a rapid growth in international travel all around the world, especially for recreational purposes. A similar trend has been recently observed in Poland. A majority of Polish tourists visit European countries, most frequently those in the Mediterranean region, but each year an increasing number of travelers opt for more exotic holiday destinations in Asia, Africa and Central America. With tropical destinations becoming increasingly popular among Polish holidaymakers, family doctors have seen a rising number of patients who seek medical advice on the health risks prevalent in hot countries and health prevention measures to be taken in the tropics. A systematic increase in the number of visits to travel medicine websites provides evidence of the growing interest in this subject. On the increasingly popular www.medycynatropikalna.pl website, we have observed a growing number of searches for information concerning health risks in South-East and South Asia (Thailand, India, Vietnam, Sri Lanka), East Africa (Tanzania/Zanzibar, Kenya), the Caribbean (Dominican Republic), as well as information on vector-borne diseases (yellow fever, malaria), food- and waterborne diseases (typhoid, poliomyelitis), zoonoses (rabies) and sexually transmitted diseases (HIV/AIDS). The article presents the basic breadth of knowledge on travel medicine that a primary care practitioner must possess in order to be able to provide pre-travel, as well as post-travel, consultation to their patients.

Key words: travel medicine, primary health care.

Korzeniewski K. Travel medicine in primary health care. Fam Med Prim Care Rev 2017; 19(3): 303-308, doi: https://doi.org/10.5114/ fmpcr.2017.69295

\section{Background}

All around the world, there has been a rapid growth in international travel, especially for recreational purposes. This has mostly been due to the development of air transport, which is now more commonly operated by low cost carriers, as well as the aging population (resulting in a higher number of travelling pensioners), an increasing number of students studying abroad and an increase in medical tourism. China's economic growth also plays a part, as currently the majority of international travelers and money spenders come from this very country. According to the World Tourism Organization (WTO), international travelers from China spend a total of 292 billion US dollars, more than the Americans (112.9 billion), Germans (77.5 billion) and the British (63.3 billion) [1]. In 1950, the number of international tourist arrivals was estimated at 50 million; in 2016, it reached 1,235 billion, and this continues to grow at a rapid rate. The biggest traveler movement is observed in Europe (50\%), Asia, Australia and Oceania (25\%), in North and South America (16\%), as well as in Africa (5\%). The world's most visited countries are France ( 84.5 million visitors), USA (77.5 million) and Spain (68.2 million) [1]. Poland was ranked 16th in terms of international tourist arrivals, with 16.7 million visitors [2]. Polish travelers, in turn, are estimated to make a total of 11 million trips abroad each year, with the most popular destinations being Germany, Italy, Great Britain, Croatia and Greece [2]. Every year, however, an increasing number of Polish travelers opt for a holiday in more exotic places in Asia, Africa or Central America. In Poland, most tourists go on a holiday with their local tour operator, yet the number of backpackers or travelers who organize a holiday trip on their own is still growing. These travelers are the ones most likely to search for health-related information. Thus, owing to the increasing number of travels to tropical destinations, more patients report to primary care practitioners to seek medical advice on risk factors prevalent in different corners of the world, along with appropriate methods of disease prevention. The article presents the basic breadth of knowledge on a new medical specialty - travel medicine, which a primary care practitioner must possess in order to be able to consult their patients on immunoprophylaxis and malaria chemoprophylaxis before they travel to tropical destinations, as well as to be able to diagnose and treat returning travelers experiencing travel-related health issues.

\section{Travel medicine websites as a modern source of information}

A systematic increase in the number of visits to travel medicine websites provides evidence of a growing interest in the subject.

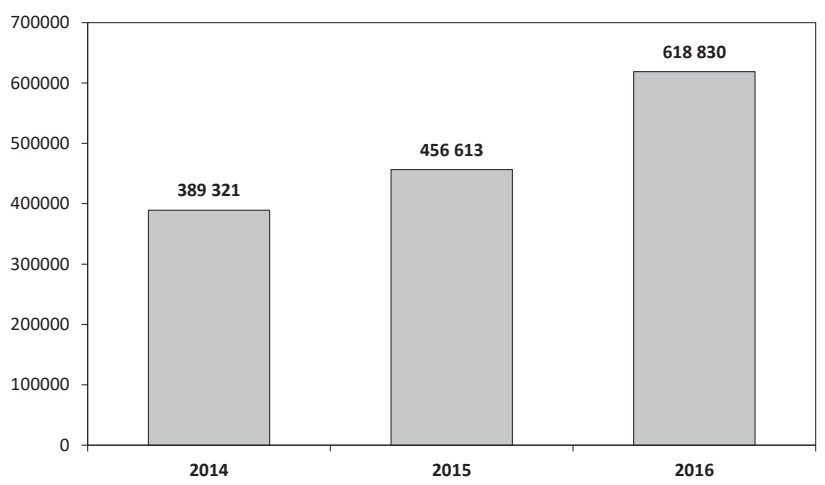

Figure 1. Number of visits to the website www.medycynatropikalna.pl between 2014 and 2016 
On the increasingly popular www.medycynatropikalna.pl website (Figure 1), a growing number of searches are made for health risks prevalent in South-East and South Asia (Thailand, India, Vietnam, Sri Lanka), East Africa (Tanzania/Zanzibar, Kenya), the Caribbean (Dominican Republic) (Table 1), as well as information on vector-borne diseases (yellow fever, malaria), foodand waterborne diseases (typhoid, poliomyelitis), zoonoses (rabies) and sexually transmitted diseases (HIV/AIDS) (Table 2).

\begin{tabular}{|c|c|c|c|c|}
\hline www.medycynatropikalna.pl & 2014 & 2015 & 2016 & Total \\
\hline $\begin{array}{l}\text { Thailand vaccinations/dis- } \\
\text { eases }\end{array}$ & 1,183 & 2,213 & 7,000 & 10,396 \\
\hline $\begin{array}{l}\text { Tanzania/Zanzibar vaccina- } \\
\text { tions/diseases }\end{array}$ & 485 & 1,675 & 3,918 & 6,078 \\
\hline Kenya vaccinations/diseases & 446 & 587 & 3,829 & 4,862 \\
\hline $\begin{array}{l}\text { Dominican Republic vaccina- } \\
\text { tions/diseases }\end{array}$ & 95 & 518 & 1,756 & 2,369 \\
\hline India vaccinations/diseases & 580 & 768 & 1,627 & 2,975 \\
\hline $\begin{array}{l}\text { Vietnam vaccinations/dis- } \\
\text { eases }\end{array}$ & 169 & 451 & 1,462 & 2,082 \\
\hline $\begin{array}{l}\text { Sri Lanka vaccinations/dis- } \\
\text { eases }\end{array}$ & 302 & 515 & 1,176 & 1,993 \\
\hline Total & 3,260 & 6,727 & 20,768 & 30,755 \\
\hline
\end{tabular}

Table 2. Most commonly accessed pages of diseases on www. medycynatropikalna.pl between 2014 and 2016 ( $n=$ number of visits)

\begin{tabular}{|l|l|l|l|l|}
\hline www.medycynatropikalna.pl & $\mathbf{2 0 1 4}$ & $\mathbf{2 0 1 5}$ & $\mathbf{2 0 1 6}$ & Total \\
\hline Yellow fever & 719 & $\mathbf{1 , 8 9 9}$ & $\mathbf{4 , 2 6 7}$ & $\mathbf{6 , 8 8 5}$ \\
\hline Typhoid fever & 544 & 959 & 2,842 & $\mathbf{4 , 3 4 5}$ \\
\hline Rabies & 278 & 917 & 2,129 & $\mathbf{3 , 3 2 4}$ \\
\hline Malaria & 120 & 139 & 1,995 & $\mathbf{2 , 2 5 4}$ \\
\hline Poliomyelitis & 114 & 550 & 1,559 & $\mathbf{2 , 2 2 3}$ \\
\hline HIV/AIDS & 744 & 1,550 & 1,498 & $\mathbf{3 , 7 9 2}$ \\
\hline Amebiasis & 149 & 533 & $\mathbf{1 , 1 6 7}$ & $\mathbf{1 , 8 4 9}$ \\
\hline Total & $\mathbf{2 , 6 6 8}$ & $\mathbf{6 , 5 4 7}$ & $\mathbf{1 5 , 4 5 7}$ & $\mathbf{2 4 , 6 7 2}$ \\
\hline
\end{tabular}

The website is more frequently visited in the period between October and January (Figure 2), i.e. the summer period, which is the peak tourist season in many tropical countries. This fact proves the growing popularity of tropical destinations among Polish travelers [3].

\section{Pre-travel consultation in a family doctor's office}

\section{Preparations for departure}

Before travelling abroad, especially to areas where environmental conditions are difficult or where infectious diseases are endemic, it is absolutely necessary to undertake certain disease prevention measures to reduce health risks. It is especially important for a traveler to obtain all the necessary information regarding the health risks prevalent in destination countries and possible health prevention measures. Travelers on package tours should receive health-related advice from their local travel agent. A tour operator is legally obliged to provide its customers with such information (Article 13 section 2 of the Act of 29 August 1997 on tourism services; Journal of Laws from 1997, No. 133, item 884); however, practice shows that when in search of medical information, travelers often have to rely on themselves, and therefore they commonly search for the necessary information online or with a primary care practitioner. Before visiting exotic destinations, travelers are recommended to have a pre-travel medical check-up and receive all the required doses of mandatory or recommended vaccinations, with a written confirmation of the doses taken in the International Certificate of Vaccination (yellow book). They should also obtain information regarding malaria chemoprophylaxis and get advice on the contents of a travel health kit. In order for a family doctor to recommend appropriate prevention measures, a patient must be ready to talk about the following subjects: the itinerary (country, part of the world), the length of stay, departure and return dates, the purpose of travel (professional, recreational), the type of accommodation (a hotel, a low-cost hostel, a tent), types of activities they are going to undertake (a beach holiday, scuba diving, mountain climbing, jungle or desert expeditions, cave exploration), chronic or ongoing conditions, pregnancy, lactation, all medications taken, the use of contraception. A physician needs to be ready to give professional advice to different groups of patients, including those with chronic conditions, including patients with: allergies (inhalation, contact, food, drug, hymenoptera venom), immunodeficiency, neoplasm/ /cancer, status post splenectomy, carriers of infectious diseases (HIV, HBV, HCV), patients with cardiovascular conditions (varicose veins, thrombosis, embolism), psychological or psychiatric problems, epilepsy, gastrointestinal disorders [4]. The data from European travel clinics indicates that pre-travel check-ups are especially popular among travelers with allergies, psychological or psychiatric problems, patients with chronic diseases, as well as women using contraception [5].

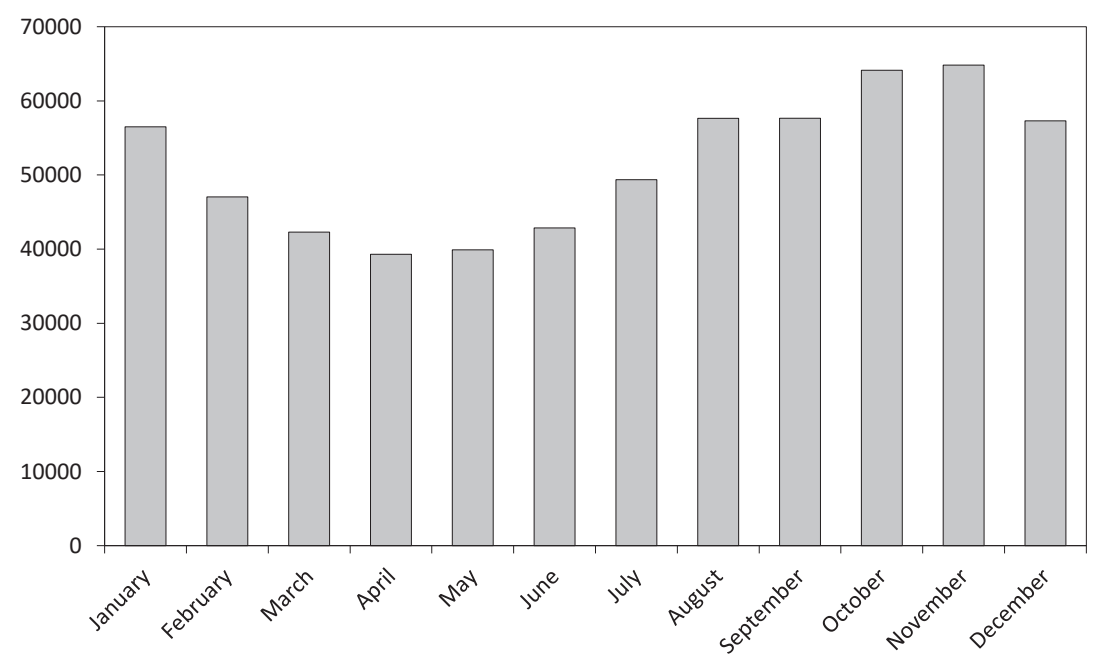

Figure 2. Number of visits to the website www.medycynatropikalna.pl in individual months $2016(n=618,830)$ 
Before receiving any travel vaccinations, a patient needs to inform their doctor about all their previous immunizations. If a traveler had never received any travel vaccinations (apart from mandatory immunizations), they should get the International Certificate of Vaccination (if a medical center is eligible to produce such document) with written confirmation of all doses received. If, however, a patient had already received some travel vaccinations, a health care practitioner has to check the information on the doses taken in the patient's yellow book and decide whether or not any more doses are necessary. All vaccinations ought to be taken 4-6 weeks before the planned departure, so that there is enough time to receive all doses of the vaccine and develop immunity. Long-term travelers who are going to work or study abroad may be required by their employer or university authorities to receive specific vaccinations.

Vaccinations against meningococcal disease and yellow fever are mandatory for all travelers to a number of different countries around the world. Both vaccines are administered in a single dose, and a booster dose is not required, according to the manufacturers' recommendations. In July 2016, the World Health Organization announced new vaccination requirements for yellow fever: "the period of validity for all certificates of vaccination against yellow fever changes from 10 years to the duration of the life of the person vaccinated, including for certificates already issued and new certificates" [6]. Vaccination against yellow fever is compulsory for travelers visiting the disease endemic countries in Africa and South America. Foreign visitors may be required to present the International Certificate of Vaccination documenting the doses they had received before entering some African countries. The author of the article was once asked to provide written confirmation of immunization against yellow fever immediately after landing in a Sub-Saharan country. Vaccination against meningococcal disease is mandatory for all travelers to Saudi Arabia going on a pilgrimage to Mecca. Visitors to Saudi Arabia are required to obtain an entry visa before departure; when submitting the application, they will be asked to state the purpose of the visit (business, VFRs, transit or religious: the Hajj or Umrah pilgrimage). If they travel for religious purposes (reserved for Muslims only), they will be obliged to receive vaccination against yellow fever, as written confirmation of immunization is routinely checked upon arrival.

The most common pre-travel vaccinations include those against diphtheria, tetanus, poliomyelitis, viral hepatitis $A$ and $B$, typhoid and rabies. Vaccines against cholera and Japanese encephalitis are also available in Poland, although these diseases have not been reported in our country. The data on pre-travel vaccinations performed on 64,000 travelers over a period of 10 years in a Swiss travel clinic indicates that the most common pre-travel vaccinations were those against viral hepatitis A (53\%), diphtheria/tetanus (46\%), yellow fever (39\%) and poliomyelitis (38\%) [5]. A health care practitioner needs to inform the patient of the necessity to receive complementary and booster doses in line with the vaccination schedule. This is usually a long-term process that needs to be monitored by the health care provider administering the initial doses of vaccines.

Antimalarial chemoprophylaxis is no more important than preventive vaccinations. The Centers for Disease Control and Prevention, as well as the World Health Organization, recommend that travelers to malaria endemic areas should use one of the following drug regimens: atovaquone/proguanil ( 1 tablet $250 \mathrm{mg} / 100 \mathrm{mg}$ once daily, 1-2 days before departure, during travel and 7 days after returning home), doxycycline ( 1 tablet or capsule $100 \mathrm{mg}$ once daily, 1-2 days before departure, throughout the stay in endemic areas and 28 days after travel), mefloquine (1 tablet $250 \mathrm{mg}$ once weekly, 1-2 weeks before travel, during travel and 4 weeks after returning home; the drug is not well-tolerated, possible side effects include neuropsychiatric disorders), chloroquine (1 tablet $500 \mathrm{mg}$ once weekly, 1-2 weeks before travel, throughout the stay in endemic areas and 4 weeks after travel). It needs to be remembered that the emergence of chloroquine-resistant plasmodium has had a significant impact on the application of chloroquine to treat malaria; currently, the drug is only being used in certain regions of the world (Central America, North Africa, some Middle East countries) [7].

The purpose of a pre-travel consultation is also to receive advice on the contents of a travel health kit. This particularly applies to travelers who are planning an adventure holiday or are likely to get involved in extreme sports. Apart from the recommended health prevention products, medications and dressing material, it is important that travelers take prescription medicines for chronic conditions and contraceptive medications for the whole period of travel. The most important medicines should be kept in the hand luggage in the original packaging, in case of a thorough inspection by border guards. When travelling by plane, travelers should keep in mind certain security requirements on the transport of liquids (drugs in the form of suspensions, syrups or cosmetics). Liquid containers larger than $100 \mathrm{ml}$ must be placed in checked baggage, while containers smaller than $100 \mathrm{ml}$ may be carried in the hand luggage, but must be stored in a sealed transparent plastic bag. Apart from prescription medicines, the travel health kit should also contain antimalarial medications (it is worth noting that apart from standard malaria treatment drug regimens, medication for stand-by emergency treatment (SBET): artemether $80 \mathrm{mg} /$ /lumefantrine $480 \mathrm{mg}$, taken for a total of 6 doses over 3 days, is available in some European countries) [8]. Additionally, travelers must not forget about taking insect repellent, antidiarrheal medication, analgesic/antipyretic, antihistamine, antibiotic, antibacterial ointments and creams, eye and ear drops, dressing materials, an extra pair of glasses or contact lenses (travelers with a sight defect), sunglasses and sunscreen. On top of this, travelers to exotic destinations need to remember about health insurance. Polish travelers who are insured through the Polish National Health Fund can obtain the European Health Insurance Card, which gives them the right to receive medical treatment in other EU member states, as well as in Iceland, Norway, Liechtenstein and Switzerland, free of charge or at a reduced cost. Travelers to all other countries are recommended to obtain travel insurance including coverage for medical treatment. However, they need to remember that basic plans offer little coverage and contain a number of exclusions, such as treatment of tropical diseases or treatment of injuries sustained while participating in extreme sports. Travelers are recommended to obtain insurance including the coverage for medical evacuation and repatriation. If travelers are planning to engage in extreme sports, e.g. high mountain climbing, they should consider insurance including coverage for rescue operations [9].

\section{Health risk assessment}

A health care practitioner offering pre-travel consultations should first become acquainted with the current epidemiological situation regarding infectious diseases (tropical and cosmopolitan) around the world. For this purpose, they are recommended to access the official WHO or CDC websites or any of the Polish websites containing information on travel medicine, e.g. www.medycynatropikalna.pl. For convenience, contagious and parasitic diseases that are endemic in tropical destinations have been divided into separate categories on the basis of their transmission modes. For instance, vector-borne diseases have been categorized as transmitted by: mosquitoes (malaria, dengue fever, chikungunya, Zika, yellow fever, filariasis), sand flies (cutaneous, mucocutaneous and visceral leishmaniasis, sand fly fever), ticks (Crimean-Congo hemorrhagic fever, tick-borne encephalitis, $Q$ fever), lice (epidemic typhus), fleas (bubonic plague, endemic typhus), tsetse flies (African trypanosomiasis), Hemiptera/true bugs (Chagas disease). Other routes of transmission will include: fecal-oral transmission (viral hepatitis $A$, typhoid fever, cholera, protozoan and helminthic parasitoses), airborne transmission (tuberculosis, meningococcal disease), 
sexual transmission (HIV/AIDS, syphilis, gonorrhea, Chlamydia infection), direct contact with animals: bites (rabies), airborne transmission ( $Q$ fever), direct physical contact with the skin of an infected animal (anthrax), consumption of foods contaminated with excrement (echinococcosis), consumption of unpasteurized dairy products or direct physical contact with contaminated excrement or secretions (brucellosis). Some diseases can also be transmitted via contact with contaminated blood, e.g. injections, blood transfusion, cosmetic procedures (HIV/AIDS, viral hepatitis $\mathrm{B}$ and $\mathrm{C}$ ), direct physical contact with contaminated soil (intestinal helminthiases, larva migrans, tetanus) or water (intestinal protozoan infections, schistosomiasis).

\section{Health precautions during travel}

During a pre-travel consultation, a traveler should receive all the basic information regarding acclimatization (drinking at least 3 to 4 liters of mineral water or isotonic drinks per day and avoiding intense physical activity in the first few days after arrival), personal hygiene, appropriate clothing, water/food and feeding hygiene, the risks from traffic accidents, as well as effective measures against insect and animal bites. To prevent insect bites, travelers are recommended to use insect repellents (containing $30-50 \%$ DEET or $20 \%$ picaridin) and mosquito nets. They should wear proper clothing (long-sleeved shirts or tops, long trousers), avoid staying outdoors from dusk to dawn, i.e. when insects are the most active, air-condition the living space and make sure that insect screens are properly installed and tightly fitting around all windows and ventilation grills. In order to prevent animal bites, travelers are strongly recommended to avoid contact with animals: both domesticated (dogs, cats) and wild animals (foxes); travelers should never approach, stroke or feed animals. If they have been bitten or scratched by an animal, they need to wash the wound thoroughly with soap and water and seek medical advice (a post-exposure vaccination is necessary in such cases). To prevent food or water borne infections, it is essential that travelers regularly wash their hands with soap and water before every meal and each time after using the toilet (if water and soap are unavailable, use disinfecting gel or tissues), drink bottled or boiled water only, avoid drinking water with ice cubes, as they may be contaminated, avoid food from street vendors and unpasteurized dairy products. Other health precautions to be taken into consideration while traveling to tropical destinations include: protection against altitude sickness in high mountain areas (acclimatization) and strong sunlight (using sunscreens with SPF), avoiding tattooing, body piercing, injections with non-sterile needles (risk of HIV, HBV, HCV infection), using condoms if travelers engage in casual sex (risk of STDs), avoiding walking barefoot in areas where local animals defecate (larva migrans) [9].

\section{After returning from a journey}

The biggest challenge facing primary care physicians lies not in pre-travel but rather in a post-travel consultation, i.e. correct diagnosis and treatment of returned travelers who have experienced some kind of a travel-related illness or condition. Over the last several years, the Polish Society of Maritime, Tropical and Travel Medicine has been organizing weekend courses related to travel medicine. After attending three such courses, participants, or rather their offices, are awarded the status of a certified travel medicine clinic and become affiliated with the national network of travel medicine offices. Primary healthcare providers running such certified offices are bound to collect information on the number and types of pre-travel vaccinations administered, antimalarial medications prescribed and antidiarrheal/dietary advice provided. They are required to prepare annual reports including all the aforementioned information and send them to the Polish Society of Maritime, Tropical and Travel Medicine. This is how the information regarding pre-travel consultations is exchanged between primary health care providers and the aforesaid society.
From the analytical point of view, the medical data gathered by medical centers which are affiliated with the GeoSentinel Surveillance Network, located across several dozen countries on six continents, are much more extensive and reliable. The primary aim of the organization is to collect information on travel-related morbidity in returned travelers. The surveillance information gathered by the affiliated members is used to track the geographic distribution of the most common diseases found in international travelers, to assess the prevalence rates of individual diseases, to describe the diagnostic and therapeutic measures taken and the length of treatment, to analyze the population of international travelers according to their age, gender, general health condition (chronic diseases), length of travel, compliance with travel health precautions, etc. The analysis of this data makes it possible to establish an effective health policy aimed at supporting the community of international travelers and also contributes to the development of a new medical discipline, i.e. travel medicine.

The most common health conditions in travelers returning from areas with harsh climate and poor sanitation include gastrointestinal disorders, fever of unknown origin, dermatoses and respiratory illnesses [10].

Gastrointestinal disorders. Acute diarrhea, mainly of bacterial (enterotoxic Escherichia coli, Campylobacter sp.) or, less frequently, of viral etiology (Norwalk, adenoviruses and rotaviruses), is the most common gastrointestinal disorder found in travelers. It is usually referred to as travelers' diarrhea, the symptoms of which usually resolve themselves after a few days. Some travelers, however, may experience persistent diarrhea that typically lasts longer than 2 weeks and is normally caused by parasites (Giardia intestinalis, Entamoeba histolytica protozoa). The diagnosis of suspected bacterial diarrhea is based on conventional microbiological methods (isolation of pathogens from fecal samples, stool culture). For the diagnosis of viral diarrhea, molecular methods (PCR) are used, while the gold standard for the diagnosis of parasitic diarrhea is the triple fecal test, i.e. examining the stool samples under light microscopy, preferably using concentration techniques: sedimentation for the detection of protozoa and flotation for the detection of helminths. Persistent diarrhea should be differentiated from noninfectious or post-infectious conditions, such as malabsorption syndrome or irritable bowel syndrome. Malabsorption syndrome arising from abnormality in digestion and absorption of food nutrients is often associated with celiac disease, cystic fibrosis or enzymatic deficiencies, e.g. lactase deficiency causing lactose intolerance. Irritable bowel syndrome, on the other hand, is an idiopathic gastrointestinal disorder of unknown etiology, characterized by abdominal pain, flatulence and defecation disorders (diarrhea or constipation) [9].

Fever of unknown origin. Malaria is the most common cause of fever in travelers returning from tropical destinations, accounting for approximately $30 \%$ of febrile illnesses in returned travelers. For this reason, when diagnosing a febrile patient, malaria should be ruled out first before proceeding with further diagnostic tests. Thick and thin blood smears remain the gold standard for laboratory diagnosis of malaria; the former is used to confirm the presence of Plasmodium, while the latter is useful for determining the species of Plasmodium and its developmental stage. The blood films used to confirm malaria are stained (e.g. with the Giemsa stain) and then evaluated under light microscopy. The sensitivity of a thick blood smear is 20-40 parasites $/ 1 \mu \mathrm{l}$, and for the thin blood smear, the sensitivity is 500-1000 parasites/ $1 \mu \mathrm{l}$. Commercially available rapid immunochromatographic tests (based on the detection of parasite antigens) and PCR assays (detection of Plasmodium - specific nucleic acids), with a sensitivity of 1 parasite $/ 20-50 \mu$ of blood, are also widely used in the diagnostics of malaria. Blood films should be examined every 8 hours over 3 consecutive days. Microscopic evaluation makes it possible to measure the degree of parasitemia (i.e. the number of infected erythrocytes per 100 
red blood cells) and to confirm the presence of vegetative forms (rings, trophozoites, schizonts). Other diseases that are endemic in tropical climates and may manifest with a fever include some viral vector-borne diseases (dengue fever, chikungunya, Zika), typhoid, viral hepatitis $A$ and acute schistosomiasis [11]. Febrile illnesses may be of non-tropical origin as well, e.g. pneumonia or pyelonephritis. It also needs to be remembered that fever may accompany dermatoses (a secondary bacterial skin infection) or injuries (burns) [12]. Most febrile illnesses have a short incubation period and tend to manifest within 4 weeks after the traveler's return. Some conditions, however, have longer incubation periods and can manifest themselves long after the traveler's return; these include Plasmodium vivax malaria, viral hepatitis and tuberculosis. Obviously, a febrile illness can manifest itself in a number of ways; the onset of fever may be gradual and be associated with bradycardia (typhoid), or abrupt as in dengue fever. Malaria, for instance, is characterized by a sudden onset of fever, which then recurs in cycles. In Plasmodium vivax and $P$. ovale infections, fever paroxysms occur periodically every 48 hours, and in $P$. malariae infection - every 72 hours. Fever paroxysms in $P$. falciparum malaria are irregular, and an elevated body temperature of varying degrees can persist throughout the duration of the symptomatic disease. In some febrile illnesses, e.g. African trypanosomiasis, fever is intermittent, and febrile paroxysms can be separate by intervals of a few days. Febrile illnesses are often associated with non-specific signs and symptoms, e.g. headaches, muscle pain, joint pain, general weakness/fatigue, skin rash or conjunctivitis, which could be attributed to a number of other viral vector-borne infections, including the increasingly prevalent dengue fever, chikungunya and Zika. In order to differentiate between the diseases, a number of other signs and symptoms need to be investigated, e.g. leucopoenia and thrombocytopoenia occur in dengue fever and chikungunya, but not in Zika. Hepatomegaly often accompanies dengue fever, but is absent in chikungunya and Zika [13].

Over the last 2 years, the Zika virus has received much attention all over the world. Last year, there were reports of an estimated 1.5 million cases of Zika in Brazil only. At present, the estimates are much lower. A total of 203,751 confirmed cases of Zika were reported globally in the period from January 01, 2015 to February 16, 2017, and the number of suspected cases was 547,184 . The highest prevalence of Zika was reported from Brazil $-130,840$ confirmed and 215,319 suspected cases [14].

Dermatoses. The most common dermatoses found in returning travelers include allergic reactions to insect bites, sunburns, pyodermas, militaria and skin rash caused by a viral infection. Generally, dermatological manifestations in returned travelers fall into two broad categories: lesions associated with fever (secondary bacterial infections, skin rash caused by a viral infection) and those not associated with fever (most dermato-

Source of funding: This work was funded by the author's resources. Conflict of interest: The author declares no conflict of interests.

\section{References}

1. World Tourism Organization. Yearbook of tourism statistics, 2017 Edition [cited: 11.03.2017]. Available from: http://statistics.unwto. org/publication/yearbook-tourism-statistics-2017-edition.

2. Ministerstwo Sportu i Turystyki RP. Turystyka w Polsce w 2015 r. [cited: 11.03.2017]. Available from: http://www.msport.gov.pl/badania-rynku-turystycznego/turystyka-w-polsce-w-2015-r-dot. (in Polish).

3. Korzeniewski K. Profile of medical information sought by Polish travelers. Fam Med Prim Care Rev 2016; 18(3): 262-267.

4. Noble LM, Willcox A, Behrens RH. Travel clinic consultation and risk assessment. Infect Dis Clin North Am 2012; 26(3): 575-593.

5. Boubaker R, Meige P, Mialet C, et al. Travellers' profile, travel patterns and vaccine practices - a 10-year prospective study in a Swiss Travel Clinic. J Travel Med 2016; 23(1): pii: tav017.

6. World Health Organization. New yellow fever vaccination requirements for travelers [cited: 12.03.2017]. Available from: http://www. who.int/ith/updates/20160727/en/.

7. Jacquerioz FA, Croft AM. Drugs for preventing malaria in travellers. Cochrane Database Syst Rev 2009; 4: CD006491.

8. Schlagenhauf P, Petersen E. Standby emergency treatment of malaria in travelers. Expert Rev Anti Infect Ther 2012; 10(5): 537-546.

9. Korzeniewski K. Medycyna podróży. Kompendium. Warszawa: Wydawnictwo Lekarskie PZWL; 2016: 36, 56-58, 75-80, 125, 311-314 (in Polish). ses). The diagnosis of skin lesions is based on identifying the

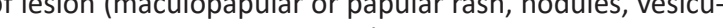
or hairy skin, armpits, groins, joints), etiological factor (insect bites, sunlight, high temperature and humidity) and associated (pruritus, pain, burning, fever). Skin conditions in remyiasis, dengue fever, chikungunya or Zika). however, most are caused by cosmopolitan pathogens [15].

in respiratory tract infections of either bacterial or viral etiology. These can be acquired in hotels, on cruise ships or passenger the spread of pathogens (influenza virus, adae, Legionella pneumoniae) is additionally facilitated by poorly developed countries, and the most common are upper respiratory tract infections (cold, pharyngitis, sinusitis), while moderate-to-severe lower respiratory tract infections (pneumonia), fication of the etiological agent, using either molecular assays this purpose; the standard imaging methods to diagnose respiratory illnesses include a sinus or chest X-ray [17].

\section{Diagnostics in returning travelers}

A primary care practitioner consulting a returning traveler has to keep in mind that some conditions of tropical etiology have an asymptomatic course, e.g. infestations with intesof several months to even years (although they show no signs terized by harsh climate and poor sanitation (long-term travelers) or travelers prone to risky behavior (consumption of food products from unknown sources, unsafe sexual practices, not all necessary diagnostic tests, even if they exhibit no signs or symptoms of a disease. The following tests are recommended erential (confirmation of eosinophilia associated with parasitic filariasis) [18], urinalysis, urea, creatinine, glucose, bilirubin, (sedimentation and flotation method), chest X-ray, abdominal ultrasonography, blood, urine and fecal cultures $[9,10]$. for travelers returning from tropical destinations: $C B C$ with dif- 
10. Freedman DO, Weld LH, Kozarsky PE, et al. Spectrum of disease and relation to place of exposure among III Returned Travelers. NEJM 2006; 354(2): 119-130.

11. Korzeniewski K, Gaweł B, Krankowska D, et al. Fever of unknown origin in returning travellers. Int Marit Health 2015; 66(2): 77-83.

12. Wilson ME, Weld LH, Boggild A, et al. Fever in returned travelers: results from the GeoSentinel Surveillance Network. Clin Infect Dis 2007; 44(12): 1560-1568

13. Korzeniewski K, Juszczak D, Zwolińska E. Zika - another threat on the epidemiological map of the world. Int Marit Health 2016; 67(1): 31-37.

14. Department of Defense (AFHSB). Global Zika Virus Surveillance Summary (22 Feb 2017). Armed Forces Health Surveillance Branch, USA [cited: 13.03.2017].

15. Korzeniewski K, Juszczak D, Jerzemowski J. Skin lesions in returning travellers. Int Marit Health 2015; 66(3): 173-180.

16. Luna LK, Panning M, Grywna K, et al. Spectrum of viruses and atypical bacteria in international air travelers with symptoms of acute respiratory infection. J Infect Dis 2007; 195(5): 675-679.

17. Korzeniewski K, Nitsch-Osuch A, Lass A, et al. Respiratory infections in travelers returning from the tropics. Adv Exp Med Biol 2015; 849: 75-82.

18. Schulte C, Krebs B, Jelinek T, et al. Diagnostic significance of blood eosinophilia in returning travelers. Clin Infect Dis 2002; 34(3): 407-411.

Tables: 2

Figures: 2

References: 18

Received: 29.03.2017

Revised: 10.04.2017

Accepted: 20.04.2017

Address for correspondence:

Col. Krzysztof Korzeniewski, MD, PhD, Assoc. Prof.

Zakład Epidemiologii i Medycyny Tropikalnej

Wojskowy Instytut Medyczny

ul. Grudzińskiego 4

81-103 Gdynia

Polska

Tel.: +48 261 266-523, +48 665 707-396

E-mail: kkorzeniewski@wim.mil.pl 